\title{
Pharmacokinetics and tolerability of a bioadhesive buccal testosterone tablet in hypogonadal men
}

\author{
R J M Ross, A Jabbar, T H Jones, B Roberts, K Dunkley, J Hall, A Long, H Levine ${ }^{1}$ and D R Cullen \\ Department of Endocrinology, Sheffield Teaching Hospitals, Sheffield S5 7AU, UK and ${ }^{1}$ Columbia Research Laboratories, Inc., Livingstone, NJ, USA \\ (Correspondence should be addressed to R J M Ross, Clinical Sciences, Northern General Hospital, Sheffield S5 7AU, UK; Email: r.j.ross@sheffield.ac.uk)
}

\begin{abstract}
Objective: A phase I single centre, open label study of the pharmacokinetics and tolerability of a buccal testosterone tablet (COL 1621) was carried out.

Design: Twelve testosterone-deficient males were treated with the buccal tablet twice daily for 7 consecutive days. Multiple blood samples were drawn for testosterone, dihydrotestosterone (DHT), bioavailable testosterone and sex hormone-binding globulin (SHBG).

Results: After COL 1621, means \pm S.D. serum testosterone level increased to a peak concentration of $26.6 \pm 5.8 \mathrm{nmol} / \mathrm{l}(7.7 \pm 1.7 \mathrm{ng} / \mathrm{ml})$ at $4.8 \pm 5.8 \mathrm{~h}$ and stayed in the eugonadal range. Steady state was achieved within the first $24 \mathrm{~h}$ and was maintained in the normal range. The bioavailable testosterone, DHT and free testosterone index followed a pattern very similar to that of testosterone. The mean serum testosterone to DHT ratio was within the normal male range throughout treatment. There was only one treatment-related adverse event (headache). Two-thirds of patients indicated that treatment with COL 1621 was acceptable and that the tablet was convenient to use. Six patients $(50.0 \%)$ preferred COL 1621 to their previous testosterone replacement therapy, two patients gave preference to their previous treatment and three patients found both treatments to be equally acceptable. Data for one patient was not available.

Conclusion: We conclude that COL 1621 can efficiently elevate serum testosterone and DHT levels in hypogonadal men within the first day of application, achieve a steady state within $24 \mathrm{~h}$ and maintain serum testosterone in the normal range with a twice-daily treatment regimen. COL 1621 provides an effective alternative oral testosterone replacement therapy that gives physiological levels of testosterone and is well tolerated by the patients.
\end{abstract}

European Journal of Endocrinology 150 57-63

\section{Introduction}

Androgen replacement therapy in hypogonadal men should attempt to produce serum concentrations of testosterone and its active metabolite, dihydrotestosterone (DHT) that are within normal ranges $(1,2)$. The most widely used testosterone preparations fall into four main categories: (a) oral, (b) intramuscular testosterone esters, (c) transdermal preparations, and (d) longacting testosterone pellets $(3,4)$. Oral preparations include tablets with intestinal absorption, i.e. testosterone undecanoate (5), as well as sublingual and buccal applications. Each route of administration has its therapeutic niche, although many recipients would prefer an oral route of administration if it were convenient, inexpensive, effective and free of adverse effects.

This report describes the pharmacokinetics of a bioadhesive testosterone buccal tablet (COL 1621) that has several advantages over currently available oral androgens. COL 1621 is a testosterone progressive hydration tablet with a matrix that consists of testosterone, monohydrated lactose, hydroxypropylmethylcellulose, corn starch and polycarbophil. COL 1621 allows for the slow release of testosterone in such a manner that stable and reliable serum testosterone concentrations are produced, and its buccal absorption avoids first-pass hepatic metabolism. Two phase I studies have been completed investigating COL 1621 administration to healthy female volunteers (data on file with Columbia Laboratories). In both studies, COL 1621 $30 \mathrm{mg}$ buccal tablets resulted in serum testosterone concentration levels that were within the normal reference range for healthy young males. The preparation was well tolerated without side effects. The present study was designed to investigate the pharmacokinetics, safety and tolerability of COL 1621 in testosteronedeficient men.

\section{Material and methods}

The study was approved by The South Sheffield Ethics Committee and all patients gave written and informed consent. 


\section{Participants}

Twelve testosterone-deficient Caucasians males, aged 26-61 years (mean: 44.4) were studied (Table 1). Two patients had primary gonadal failure and the remaining 10 patients had hypopituitarism. Prior to study entry, all 12 patients were receiving testosterone replacement therapy: nine patients with Sustanon ${ }^{\circledR}$ (testosterone administered by the intramuscular route), two patients with Andropatch ${ }^{\circledR}$ (transdermally delivered testosterone) and one patient with Profasi ${ }^{\circledR}$ (subcutaneously injected human chorionic gonadotropin). At study entry, none of the patients were currently smoking; five patients had stopped smoking and the remaining seven patients had never smoked.

Patients were testosterone deficient, defined as serum testosterone level $<8 \mathrm{nmol} / \mathrm{l}(2.5 \mathrm{ng} / \mathrm{ml})$ at the end of a 1-4-week washout period; 1 week for patients on transdermal testosterone and 4 weeks for patients on intramuscular testosterone replacement. Inclusion criteria were males, aged between 18 and 65 years, with a body mass index (BMI) $<35 \mathrm{~kg} / \mathrm{m}^{2}$. Exclusion criteria were current use of corticosteroids (unless for replacement therapy), moderate to severe symptoms of benign prostatic hypertrophy, prostate-specific antigen $>2.5 \mu \mathrm{g} / \mathrm{l}($ men $<50$ years of age) or $>4.5 \mu \mathrm{g} / \mathrm{l}$ (men between 50 and 65 years of age) and a history or suspicion of prostatic cancer.

\section{Study design}

This was an open-label study conducted at a single investigational site and consisted of the following phases:

(1) Pre-inclusion visit: patient eligibility was determined at a pre-inclusion visit when a medical history was obtained and a physical examination and a standard 12-lead electrocardiogram (ECG) performed. Blood was collected for analysis of routine haematology, serum biochemistry, total testosterone, DHT and sex hormone-binding globulin (SHBG).

Table 1 Baseline characteristics of the hypogonadal men.

\begin{tabular}{lccc}
\hline Variable & $\boldsymbol{n}$ & Mean & SD or range \\
\hline Age (years) & 12 & 44.4 & $26-61$ \\
Height (cm) & 12 & 175.8 & 9.6 \\
Body weight $(\mathrm{kg})$ & 12 & 96.9 & 17.2 \\
BMl $\left(\mathrm{kg} / \mathrm{m}^{2}\right.$ ) & 12 & 31.5 & 4.4 \\
Blood pressure (mmHg) & & & \\
Systolic & 12 & 127 & 15.5 \\
Diastolic & 12 & 79 & 9.3 \\
Causes of hypogonadism & & & \\
Primary hypogonadism & 2 & & \\
Secondary hypogonadism & 10 & & 1.62 \\
Haemoglobin (g/dl) & 12 & 14.9 & 3.63 \\
Serum testosterone (nmol/l) & 12 & 3.73 & \\
\hline
\end{tabular}

(2) Dosing phase: this phase consisted of 8 consecutive study days. On each study day, patients attended the trial site in the morning following an overnight fast. During the study day, the patient remained under supervision at the trial site. Physical activity and food and fluid intake were standardised. On each study day, days $1-6$, COL 1621 was applied in the morning (at approximately $0900 \mathrm{~h}$ ) and in the evening (at approximately $2100 \mathrm{~h}$ ). Half an hour after administration of the buccal tablet, a check was made to ensure that the tablet had been correctly applied to the gum. Details on adverse events (AEs), if any, were noted and the patient's gums were inspected for signs of mucosal irritability. Information on medical problems and use of concomitant medications was recorded. Patients rated the acceptability of the COL 1621 treatment regimen.

(3) Post-dosing follow-up: a follow-up visit for assessment of safety and tolerability took place within 7 days of the last study day.

\section{Treatment}

Treatment consisted of twice-daily administration for 7 days of $30 \mathrm{mg}$ testosterone formulated as a bioadhesive buccal tablet (COL 1621) supplied by Columbia Laboratories, France. The patient placed the tablet above the right or left incisor tooth (Fig. 1) with the rounded side against the gum and held it with a finger for $30 \mathrm{~s}$. The tablet was left in situ for $12 \mathrm{~h}$.

\section{Laboratory analyses}

On study days 1-3 and 6, blood samples for measurement of serum testosterone were drawn twice daily at approximately $0900 \mathrm{~h}$ (time $=0 \mathrm{~h}$, i.e. after tablet removal and before application of a new tablet) and $1700 \mathrm{~h}$ (time $=8 \mathrm{~h}$ ). On study days $7-8$, a total of 34 blood samples were drawn at the following (scheduled) time points: $-0.25,0.25,0.5,0.75,1.0,1.5$, $2.0,4.0,6.0,8.0,10.0,12.0,12.25,12.5,12.75$, $13.0,13.5,14.0,15.0,16.0,18.0,20.0,24.0$, $24.25,24.5,24.75,25.0,25.5,26.0,27.0,28.0$, $30.0,32.0$ and $36.0 \mathrm{~h}$ for measurement of serum testosterone.

On study days 7-8, a total of 12 blood samples were drawn at the following (scheduled) time points -0.25 , $0.5,1.0,4.0,8.0,12.0,16.0,20.0,24.0,26.0,30.0$ and $36.0 \mathrm{~h}$ for serum DHT and SHBG.

\section{Hormone assays}

All samples from individual patients were assayed in the same batch. Testosterone and SHBG were measured 

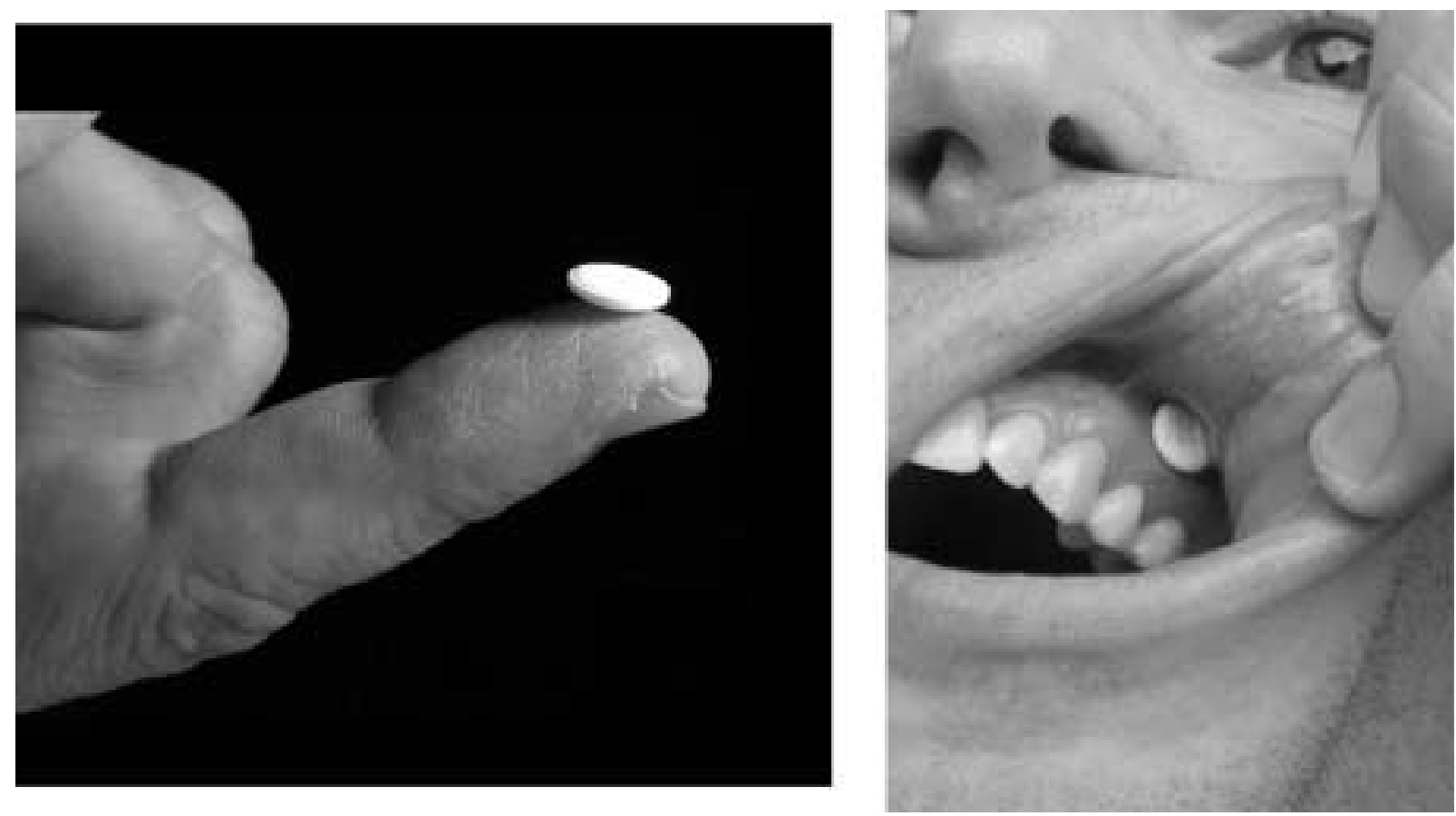

Figure $1 \mathrm{COL} 1621$ tablet (left) applied to gum (right).

by enzyme-enhanced chemiluminescence (DPC, Los Angeles, CA, USA). For testosterone the interassay coefficient of variation $(\mathrm{CV})$ at 1.7 and $20.0 \mathrm{nmol} / \mathrm{l}$ was 24.0 and $7.0 \%$ and for SHBG the interassay $\mathrm{CV}$ at 19.3 and $37.0 \mathrm{nmol} / \mathrm{l}$ was 6.6 and $7.3 \%$. DHT was measured by radio-immunoassay (DRG Instruments GmbG, Marburg, Germany) and the interassay CV at $1.46 \mathrm{nmol} / \mathrm{l}$ was $16.0 \%$. The free testosterone index (FTI) was calculated as the ratio of total testosterone/ SHBG $\times 100(6)$. The normal ranges for assays used were testosterone $(10-35 \mathrm{nmol} / \mathrm{l})$ and DHT $(1.0-$ $2.9 \mathrm{nmol} / \mathrm{l})(2,7)$. Percentage bioavailable testosterone was assayed using an adaptation of the methods described by Tremblay and Dube (8). Testosterone in the test serum is removed by the addition of activated charcoal, and replaced by ${ }^{3} \mathrm{H}$-labelled testosterone, which binds to SHBG and other plasma proteins, in equimolar concentrations as the native testosterone. SHBG-bound testosterone is then precipitated out of the sample by the addition of cold ammonium sulphate. The remaining ${ }^{3} \mathrm{H}$-testosterone, comprising the unbound fraction and the fraction weakly bound to albumin, are then measured in the supernatant using a beta counter. In the present study, this was undertaken as follows: $400 \mu \mathrm{l}$ of activated charcoal were added to duplicate $400 \mu \mathrm{l}$ of serum and incubated for $30 \mathrm{~min}$ at room temperature. The samples were then spun at 3500 r.p.m. for $20 \mathrm{~min}$ at $2-8{ }^{\circ} \mathrm{C}$. Aliquots $(200 \mu \mathrm{l})$ of the resultant solution were then added to $50 \mu \mathrm{l}$ of ${ }^{3} \mathrm{H}$-testosterone, mixed and incubated at $37^{\circ} \mathrm{C}$ for $2 \mathrm{~h}$. The samples were then chilled on ice, and $200 \mu \mathrm{l}$ of cold, saturated $(6 \mathrm{mmol} / \mathrm{l})$ ammonium sulphate added. The samples were then mixed, and centrifuged at 3500 r.p.m. for $20 \mathrm{~min}$ at $4^{\circ} \mathrm{C}$. A $200 \mu \mathrm{l}$ volume of the supernatant was then removed into a counting vial, $3 \mathrm{ml}$ of scintillation fluid added, and the remaining ${ }^{3} \mathrm{H}$-labelled testosterone radioactive tracer measured using a beta counter. Percentage bioavailable testosterone was calculated using the formula: \% bioavailable testosterone $=$ average of duplicates (d.p.m.)/blank (d.p.m.) × 100 .

The concentration of bioavailable testosterone was then calculated using the following formula: bioavailable testosterone $(\mathrm{nmol} / \mathrm{l})=\%$ bioavailable $\times$ total testosterone/100. The intra- and interassay CVs were $<5 \%$ and $<8 \%$ respectively.

\section{Pharmacokinetic evaluation}

The following pharmacokinetic variables were assessed: peak serum concentration $\left(C_{\max }\right)$; average serum concentration during the entire 7-day dosing phase $\left(C_{\text {AVGtot }}\right)$ and at steady state on dosing days $7 / 8$ $\left(C_{\mathrm{AVG} 24}\right)$; time to reach peak serum concentration $\left(T_{\max }\right)$; area under the concentration-time curve during the entire dosing phase $\left(\mathrm{AUC}_{\mathrm{tot}}\right)$ and at steady state on dosing days $7 / 8\left(\mathrm{AUC}_{24}\right)$; and time to achieve steady state.

\section{Safety and tolerability}

According to the protocol, AE was defined as any symptom and/or clinically significant laboratory abnormality that developed or increased in severity during the course 
of the study. AEs were assessed during the time window of study day 1 during the dosing phase until 30 days following administration of the final dose of COL 1621, and were recorded regardless of intensity and perceived causal relationship to the study drug. Haematology, serum biochemistry and urinalysis variables were measured at the pre-inclusion and post-dosing followup visits. Standard 12-lead ECGs were recorded at the pre-inclusion and post-dosing follow-up visits. Vital signs blood pressure (BP) and heart rate (HR) were measured at the pre-inclusion visit, at scheduled time points during the dosing phase and at the post-dosing follow-up. Finally, patients rated the acceptability of using the COL 1621 tablet using a questionnaire.

\section{Statistical analysis}

The pharmacokinetic profiles of total testosterone, FTI and DHT were assessed by non-compartmental estimation techniques using WinNonlin pharmacokinetic software (Professional version 3.1, Pharsight, NJ, USA). All parameters were calculated using the actual rather than planned times of blood sampling. To determine if total testosterone concentrations had reached steady state by the second day of dosing, the four predose concentrations on days 2, 3, 6 and 7 were compared by linear regression and aggregate ANOVA techniques. Concentrations were logarithmically transformed before analysis. The linear regression ANOVA model used the regression procedure and included the factors day and patient. Steady state was concluded if the parameter estimates (slopes) of the factors day and patient were both statistically indistinguishable from zero. All values are given as means \pm s.D.

\section{Results}

\section{Pharmacokinetics}

Pre-treatment serum testosterone levels were low in all patients, consistent with hypogonadism (Fig. 2). After COL 1621, the group serum testosterone levels increased to a mean \pm S.D. peak concentration of $26.6 \pm 5.8 \mathrm{nmol} / \mathrm{l}$ at $4.8 \pm 5.8 \mathrm{~h}$ and stayed uniformly in the eugonadal range $(10-35 \mathrm{nmol} / \mathrm{l})$. Steady state was achieved within the first $24 \mathrm{~h}$ of treatment and was maintained in the normal range between 14.5 and $24.2 \mathrm{nmol} / \mathrm{l}$ (mean $19.3 \mathrm{nmol} / \mathrm{l}$ ). The DHT levels, the bioavailable fraction of testosterone and the FTI followed a similar pattern to that of testosterone (Fig. 3). The mean testosterone/DHT ratio was within the normal male range throughout treatment (normal ratio: 9-12, data not shown). The $C_{\max 1-7 \mathrm{D}}$ concentration (Table 2) reached during the 7 -day dosing phase was $31.5 \mathrm{nmol} /$ l, i.e. high in the normal reference range for serum testosterone. The $C_{\max 1-7 \mathrm{D}}$ (maximum observed serum concentration during the dosing phase, i.e. from first sampling time on day 1 to last sampling

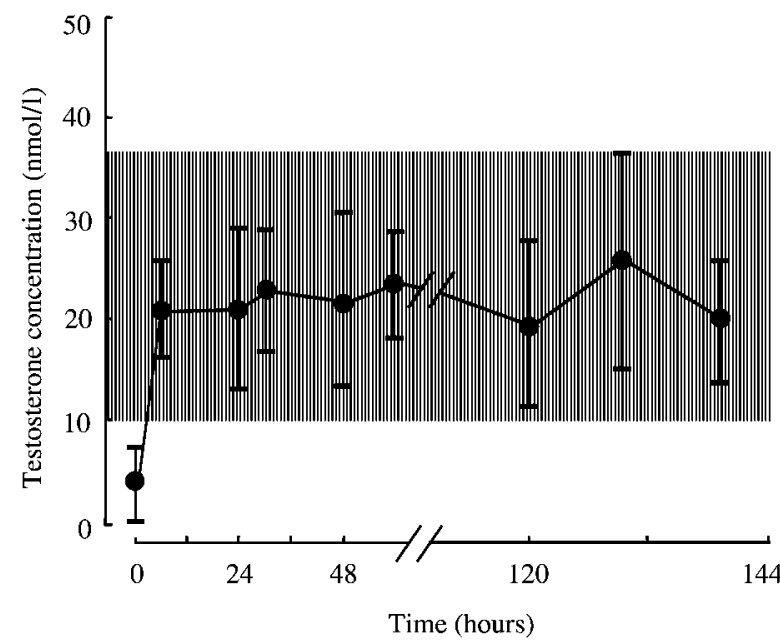

Figure 2 Serum testosterone levels $(\mathrm{nmol} / \mathrm{l})$ during repeat dosing of COL 1621 (means \pm S.D.).

time on day 8) was higher or equal to the upper limit of the reference range $(35 \mathrm{nmol} / \mathrm{l})$ in two patients and was within the normal reference range in the remaining 10 patients. The mean serum testosterone level for all patients during the dosing phase was $19.3 \mathrm{nmol} / \mathrm{l}$ and well within the normal reference range in all 12 patients. The group mean maximum $\left(C_{\max 24}\right)$ and minimum $\left(C_{\min 24}\right)$ total testosterone was $26.7 \mathrm{nmol} / \mathrm{l}$ and $11.8 \mathrm{nmol} / \mathrm{l}$ respectively. In all individual patients the $C_{\max 24}$ was above the lower limit of the normal range, whereas in four of the 12 patients $C_{\min 24}$ was below the lower limit.

Fourteen hours after application of the final COL 1621 tablet, the mean serum testosterone had fallen to $10.4 \mathrm{nmol} / \mathrm{l}$ and at $12 \mathrm{~h}$ post-removal, the mean serum testosterone concentration had further decreased to $3.4 \mathrm{nmol} / \mathrm{l}$ (Fig. 3). The DHT levels, the bioavailable testosterone and the FTI followed a pattern very similar to that of testosterone.

\section{Safety and tolerability}

There was only one treatment-related AE (headache) reported during the study. A case of mild gingivitis was considered to be non-related to COL 1621. No clinically relevant changes in serum haematology or biochemistry were observed.

\section{Patients' acceptability}

Two-thirds of patients indicated that treatment with COL 1621 was acceptable and the tablet easy to use. Eight patients reported between two and eight occasions (mean 3.6) when they had problems with COL 1621 sticking to the gum, however this did not always require replacement of the tablet. In response to a pre-designed questionnaire, six patients $(50.0 \%)$ 

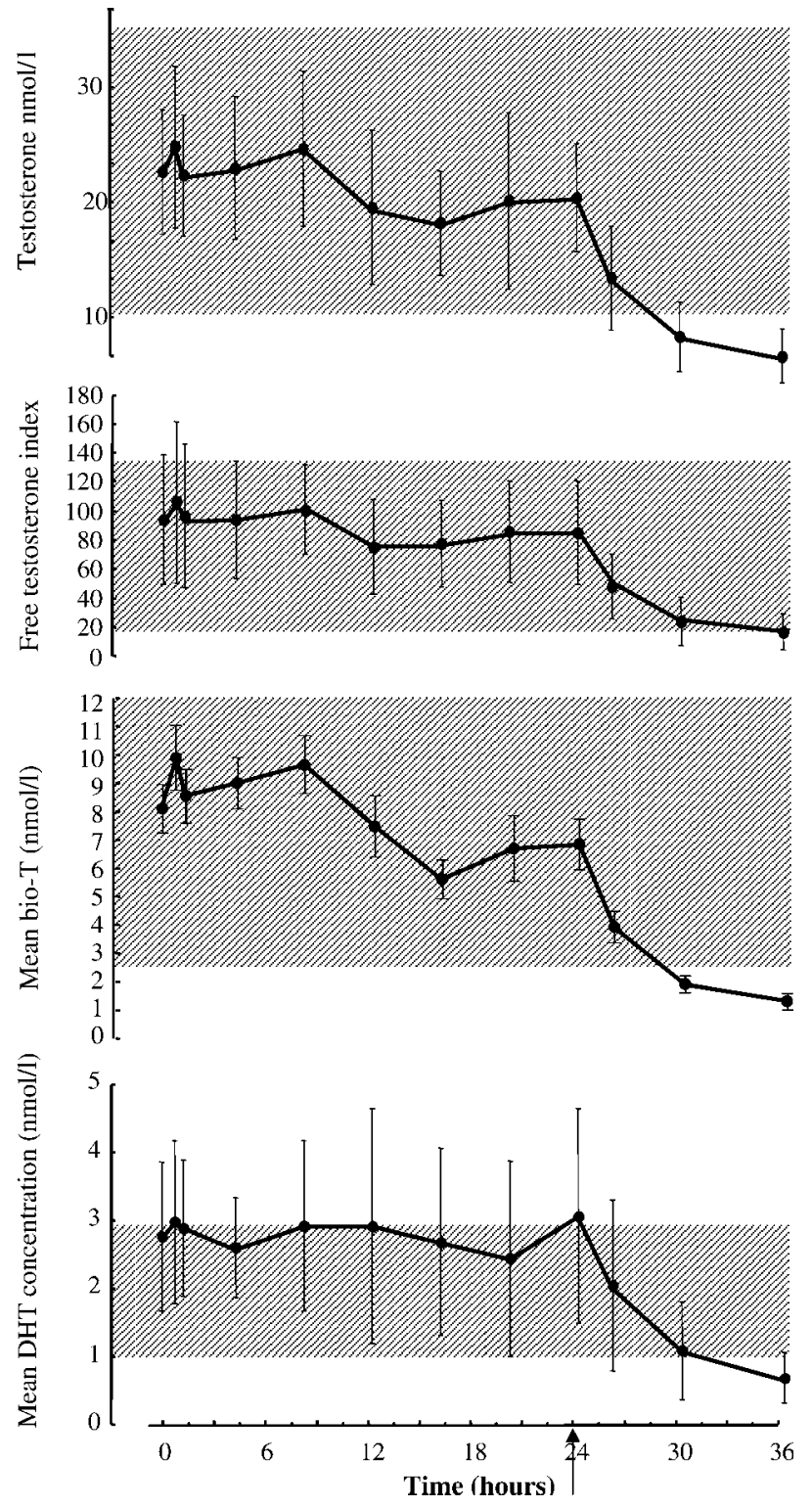

Figure 3 Serum testosterone, FTI, bioavailable testosterone (bio-T) and DHT levels on study days $7 / 8$ with administration of buccal tablet of COL 1621 at 0 and $12 \mathrm{~h}$ and removal at $24 \mathrm{~h}$ (means \pm S.D.).

preferred COL 1621 to their previous testosterone replacement therapy, two patients preferred their previous treatment and three patients found both treatments to be equally acceptable. Data for one patient was not available.

\section{Discussion}

In this study, we have shown that testosterone administered twice daily as a bioadhesive buccal tablet to hypogonadal men resulted in a physiological increase in serum testosterone levels with parallel and appropriate increases in serum DHT, bioavailable testosterone
Table 2 Pharmacokinetics of testosterone, FTI and DHT during 7 days of treatment with COL 1621 (30 mg testosterone).

\begin{tabular}{|c|c|c|}
\hline Parameter & Mean & SD \\
\hline \multicolumn{3}{|l|}{ Testosterone } \\
\hline$C_{\max 1-7 \mathrm{D}}(\mathrm{nmol} / \mathrm{l})$ & 31.5 & 7.1 \\
\hline$C_{\max 24}(\mathrm{nmol} / \mathrm{l})$ & 26.7 & 6.0 \\
\hline$C_{\min 24}(\mathrm{nmol} / \mathrm{l})$ & 11.8 & 4.7 \\
\hline$C_{\text {AVGtot }}(\mathrm{nmol} / \mathrm{l})$ & 19.3 & 3.2 \\
\hline$C_{\mathrm{AVG} 12}(\mathrm{nmol} / \mathrm{l})$ & 19.6 & 5.0 \\
\hline$C_{\text {AVG24 }}(\mathrm{nmol} / \mathrm{l})$ & 18.2 & 5.0 \\
\hline$T_{\max 1-7 \mathrm{D}}(\mathrm{h})$ & 97.1 & 55.4 \\
\hline$T_{\max 24}(\mathrm{~h})$ & 4.8 & 5.8 \\
\hline$T_{\min 24}(\mathrm{~h})$ & 12.0 & 5.0 \\
\hline$T_{1 / 2, z}(\mathrm{~h})$ & 5.7 & 2.5 \\
\hline \multicolumn{3}{|l|}{$\mathrm{FTI}^{1 / 2, z(11)}$} \\
\hline$C_{\max }(\mathrm{nmol} / \mathrm{l})$ & 124.25 & 46.94 \\
\hline$C_{\text {AVGtot }}(\mathrm{nmol} / \mathrm{l})$ & 71.87 & 23.85 \\
\hline$C_{\text {AVG24 }}(\mathrm{nmol} / \mathrm{l})$ & 87.68 & 29.53 \\
\hline$T_{\max }(\mathrm{h})$ & 6.59 & 8.05 \\
\hline \multicolumn{3}{|l|}{ DHT } \\
\hline$C_{\max }(\mathrm{nmol} / \mathrm{l})$ & 4.02 & 1.65 \\
\hline$C_{\text {AVGtot }}(\mathrm{nmol} / \mathrm{l})$ & 2.24 & 1.04 \\
\hline$C_{\mathrm{AVG} 24}(\mathrm{nmol} / \mathrm{l})$ & 2.77 & 1.16 \\
\hline$T_{\max }(\mathrm{h})$ & 6.83 & 7.54 \\
\hline
\end{tabular}

$C_{\max 1-7 \mathrm{D}}=$ maximum observed serum concentration (during the dosing phase, i.e. from first sampling time on day 1 to last sampling time on day 8). $C_{\max 24}=$ total testosterone maximum observed serum concentration during the last two consecutive dosing intervals on days $7 / 8 . C_{\min 24}=$ total testosterone minimum observed serum concentration during the last two consecutive dosing intervals on days $7 / 8$. $C_{\mathrm{AvG}}$ tot $=$ time-averaged serum concentration (during the dosing phase, i.e. from first sampling time on day 1 to last sampling time on day 8 ). $C_{\text {AVG12 }}=$ time-averaged steady-state serum concentration from $T=0$ to $T=12.0 \mathrm{~h}$ on day $7 . C_{\mathrm{AVG} 24}=$ average serum concentration at steady state from $T=0$ on day 7 to $T=24.0 \mathrm{~h}$ on day $8 . T_{\max 1-7 \mathrm{D}}=$ time to reach the maximum serum concentration (during the dosing phase, i.e. from first sampling time on day 1 to last sampling time on day 8). $T_{\max 24}=$ total testosterone time to reach the maximum serum concentration during the last two consecutive dosing intervals on days $7 / 8$. $T_{\min 24}=$ total testosterone time to reach the minimum serum concentration during the last two consecutive dosing intervals on days $7 / 8$. $T_{1 / 2, z}=$ apparent terminal elimination half-life determined on day 8 after the last tablet was removed.

and FTI. The treatment was well tolerated and 50\% of patients preferred the buccal testosterone to their previous therapy.

For testosterone replacement in testosteronedeficient males, the optimal level of testosterone (total) is of the order of $10-35 \mathrm{nmol} / \mathrm{l}(1,2)$. In all 12 patients treated with COL 1621, the average serum testosterone concentration observed during the 7-day dosing interval was well within the therapeutic window, ranging from 14.6 to $24.5 \mathrm{nmol} / \mathrm{l}$ (mean: $19.3 \mathrm{nmol} / \mathrm{l})$. This pharmacokinetic profile is not seen with oral preparations. Oral testosterone undecanoate produces wide fluctuations in testosterone serum levels and is best suited as a supplement to reduced but still present endogenous androgen levels, since it does not fully suppress the pituitary (5). Sublingual testosterone produces a rapid increase in testosterone levels which decline to below the normal range within $2 \mathrm{~h}(9)$. In a pilot study of buccal therapy, 13 hypogonadal men were given an active buccal tablet containing $10 \mathrm{mg}$ of testosterone (10). In this study, 
patients showed peak serum testosterone levels well above the normal reference range, which only returned to baseline at $4-6 \mathrm{~h}$, such that testosterone levels remained in the supraphysiological range for about 1.5-4.0 $\mathrm{h}$ after buccal administration. In contrast, COL 1621 is a unique buccal testosterone formulation that allows for sustained absorption due to its bioadhesive properties and controlled release due to its progressive hydration. In our study with COL 1621, it is to be noted that the testosterone concentration even at $C_{\max }$ did not rise above the physiological range in 10 out of 12 patients. This contrasts with the pharmacokinetics of intramuscular injected testosterone preparations, which often produce testosterone levels above the upper limit of normal for several days after administration. The pharmacokinetic profile of transdermal testosterone gel also produces a peak testosterone level above the normal range on repeat application for 7 days (11). The pharmacokinetics of the scrotal transdermal system are an initial rise to a maximum at $2-4 \mathrm{~h}$ after application, maintained levels in the normal range for the designated application period, and after removal testosterone levels quickly return to baseline values (12). This kinetic release profile is considered to be excellently adjusted to WHO requirements of testosterone levels (13). The pharmacokinetic profile of the non-scrotal transdermal patch demonstrated that the morning testosterone concentrations were also within the normal range (14).

The impact of the buccal testosterone tablets on levels of testosterone metabolite is of particular interest. COL 1621 gave constant physiological levels of both testosterone and mean DHT which were mainly in the upper range of normal although some individuals had high DHT values. In contrast, the trans-scrotal delivery system provides testosterone concentrations within normal ranges, but the serum DHT levels are elevated by four- to tenfold (15-17).

A large proportion (around 70\%) of circulating testosterone is tightly bound to SHBG and is not bioavailable. Only $1 \%$ and $3 \%$ of testosterone circulates unbound as free testosterone, while the remainder is loosely bound to albumin. The free and albuminbound portions are bioavailable. We have assayed the bioavailable fraction and calculated the FTI to assess other parameters of testosterone status. Both these parameters followed a pattern similar to testosterone and DHT.

In terms of safety and patient tolerability, repeat dosing of COL 1621 applied on the buccal mucosa was found to be safe and well tolerated. Only one AE (headache) was reported during the study. A mild case of gingivitis was observed at the post-dosing follow-up but was not thought to be related to the drug. Two-thirds of patients found the COL 1621 regimen to be an easy and acceptable form of testosterone replacement therapy. Fifty per cent preferred COL 1621 to their previous testosterone replacement therapy. In contrast, the acceptability of the scrotal patch by patients has been as low as $22 \%$ (13). Tolerability evaluations conducted in men treated for up to 48 months with nonscrotal transdermal patch showed that local reactions at the application site were the most commonly reported AE, occurring in 65 of 122 (53\%) patients. Application site reactions included pruritus, blisters, erythema and vesicles and resulted in treatment withdrawal in $9.8 \%$ of patients $(11,18)$.

\section{Conclusions}

We conclude that COL 1621 can efficiently elevate serum testosterone and DHT levels in hypogonadal men within the first day of application, achieve a steady state within $24 \mathrm{~h}$ and maintain serum testosterone in the normal range with a twice-daily regimen. It provides an effective alternative oral testosterone replacement therapy that gives physiological levels of testosterone and is well tolerated by the patients.

\section{Acknowledgements}

We are grateful to Dr D Kapoor and Dr R Robinson for medical supervision of the study patients.

\section{References}

1 WHO. 1992 guidelines for use of androgens in men. Geneva: WHO, 2002

2 Bhasin S. Clinical review 34: androgen treatment of hypogonadal men. Journal of Clinical Endocrinology and Metabolism 199274 1221-1225.

3 Cantrill JA, Dewis P, Large DM, Newman M \& Anderson DC. Which testosterone replacement therapy? Clinical Endocrinology $19842197-107$.

4 Wang C \& Swerdloff RS. Androgens. In Textbook of Pharmacology. pp 683-694. Eds CM Smith \& AM Raynaud. Philadelphia: WB Saunders, 1991.

5 Neischlag E \& Behre HM. Pharmacology and clinical uses of testosterone. In Testosterone: Action, Deficiency and Substitution, pp 294-328. Eds E Neishlag \& HM Behre. Berlin: Springer, 1998.

6 DPC Technical Report, Los Angeles, CA, USA

7 Tan KC, Shiu SW \& Kung AW. Alterations in hepatic lipase and lipoprotein subfractions with transdermal testosterone replacement therapy. Clinical Endocrinology 199951 765-769.

8 Tremblay RR \& Dube JY. Plasma concentrations of free and non-TeBG bound testosterone in women on oral contraceptives. Contraception 197410 599-605.

9 Stuenkel CA, Dudley RE \& Yen SS. Sublingual administration of testosterone-hydroxypropyl-beta-cyclodextrin inclusion complex simulates episodic androgen release in hypogonadal men. Journal of Clinical Endocrinology and Metabolism 1991 72 1054-1059.

10 Dobs AS, Hoover DR, Chen MC \& Allen R. Pharmacokinetic characteristics, efficacy, and safety of buccal testosterone in hypogonadal males: a pilot study. Journal of Clinical Endocrinology and Metabolism $1998 \mathbf{8 3} 33-39$.

11 Wang C, Berman N, Longstreth JA, Chuapoco B, Hull L, Steiner B et al. Pharmacokinetics of transdermal testosterone gel in hypogonadal men: application of gel at one site versus four sites: a General Clinical Research Center Study. Journal of Clinical Endocrinology and Metabolism 200085 964-969. 
12 Atkinson LE, Chang YL \& Snyder PJ. Long term experience with testosterone replacement through scrotal skin. In Testosterone: Action, Deficiency and Substitution, pp 365-388. Eds E Neishlag \& HM Behre. Berlin: Springer, 1998.

13 Behre HM, von Eckardstein S, Kliesch S \& Nieschlag E. Long-term substitution therapy of hypogonadal men with transscrotal testosterone over 7-10 years. Clinical Endocrinology $1999 \quad \mathbf{5 0}$ 629-635.

14 Meikle AW, Arver S, Dobs AS, Sanders SW, Rajaram L \& Mazer NA. Pharmacokinetics and metabolism of a permeation-enhanced testosterone transdermal system in hypogonadal men: influence of application site - a clinical research center study. Journal of Clinical Endocrinology and Metabolism 199681 1832-1840.

15 Bals-Pratsch M, Knuth UA, Yoon YD \& Nieschlag E. Transdermal testosterone substitution therapy for male hypogonadism. Lancet $19862943-946$
16 Bals-Pratsch M, Langer K, Place VA \& Nieschlag E. Substitution therapy of hypogonadal men with transdermal testosterone over one year. Acta Endocrinologica 1988118 7-13.

17 Ahmed SR, Boucher AE, Manni A, Santen RJ, Bartholomew M \& Demers LM. Transdermal testosterone therapy in the treatment of male hypogonadism. Journal of Clinical Endocrinology and Metabolism $198866546-551$.

18 Meikle AW, Mazer NA, Moellmer JF, Stringham JD, Tolman KG, Sanders SW et al. Enhanced transdermal delivery of testosterone across nonscrotal skin produces physiological concentrations of testosterone and its metabolites in hypogonadal men. Journal of Clinical Endocrinology and Metabolism 1992 74 623-628.

Received 17 June 2003

Accepted 13 October 2003 